\title{
Sistem Informasi E-Guest Book Pada PT. Halliburton Indonesia
}

\author{
Tri Cahyo Nugroho*1, Nadia Yulandha ${ }^{2}$, Nurazizah ${ }^{3}$ \\ ${ }^{1}$ Program Studi Akuntansi Universitas Raharja, ${ }^{2,3}$ Program Studi Sistem Informasi \\ Universitas Raharja \\ e-mail: *1 tricahyo.nugroho@raharja.info, ${ }^{2}$ nadia.yulandha@raharja.info, \\ nnurazizahnur@raharja.info
}

\begin{abstract}
Abstrak
Sistem informasi adalah satu dari beberapa dari teknologi yang sangat diperlukan oleh perusahaan atau Instansi untuk melakukan pengolahan data sebagimana data merupakan aset terpenting untuk perusahaan. Dalam meningkatkan kualitas PT. Halliburton Indonesia untuk mempermudah Real Astate Team dalam mengolah data tamu, maka pembutan Buku tamu berbasis $W e b$ diperlukan. Pada sistem yang berjalan saat ini petugas mengalami kesulitan untuk memproses data pengunjung pada PT. Halliburton Indonesia. Meskipun sudah menggunakan teknologi komputer sebagai sarana dalam pengolahan data, namun dalam mengolah data buku tamu masih dilakukan secara manual kedalam berkas. Dari masalah yang dijelaskan maka data mengenai tamu masih banyak terjadi kesalahan, kurang akurat, tidak up to date dan masih terjadi keterlambatan dalam membuat dan menyampaikan laporan kepada pimpinan. Pada penelitian ini, penelitian menggunakan metode pengumpulan data yaitu: observasi, wawancara, dan literatur review (studi pustaka). Dalam analisis menggunakan metode analisis PIECES. Selanjutnya, design sistem yang berjalan menggunakan Unified Modeling Language (UML) diantaranya: Use Case diagram, Activity diagram dan, Sequence diagram, Bahasa Pemrograman menggunakan PHP, MySQL sebagai database dan Sublime Text 3 untuk Text Editor. Hasil dari penelitian adalah berupa Sistem Informasi Buku tamu secara terdatabase atau berbasis Web dapat memudahkan petugas untuk mencari data serta menghasilkan data yang lebih akurat.
\end{abstract}

Kata Kunci: Sistem Informasi, E-Guest Book, Web

\begin{abstract}
Information systems are one of several technologies that are needed by companies or agencies to process data as data is the most important asset for the company. In improving the quality of PT. Halliburton Indonesia to make it easier for the Real Astate Team to process guest data, making a Web-based Guest Book is required. In the current system, officers have difficulty processing visitor data at PT. Halliburton Indonesia. Even though you have used computer technology as a means of processing data, processing guestbook data is still done manually into files. From the problems described, the data regarding guests still has many errors, is inaccurate, not up to date and there are still delays in making and submitting reports to the leadership. In this study, the study used data collection methods, namely: observation, interviews, and literature reviews (literature review). In the analysis using the PIECES analysis method. Furthermore, the system design that runs using the Unified Modeling Language (UML) includes: Use Case diagrams, Activity diagrams and, Sequence diagrams, Programming Language using PHP, MySQL as database and Sublime Text 3 for Text Editor. The result of the research is a database or web-based guestbook information system which makes it easier for officers to search for data and to produce more accurate data.
\end{abstract}


Keywords: Information Systems, Guestbooks, PIECES, UML

\section{PENDAHULUAN}

Dalam perkembangan teknologi yang semakin berkembang, teknologi informasi paling diperlukan oleh banyak orang. Dengan berkembang nya globalisasi itu masyarakat dipermudah dalam menyelesaikan permasalahan yang ada dengan memanfaatkan teknologi serta kecepatan, keakuratan dan ketepatan dalam penyajian informasi sehingga pekerjaanmendapatkan hasil yang maksimal. PT. Halliburton Indonesia yaitu perusahaan di bidang jasa eksploitasi, eksplorasi, gas bumi dan penyulingan minyak. Demi meningkatkan kualitas PT. Halliburton Indonesia untuk mempermudah Real Astate Team dalam mengolah data tamu maka pembutan Buku Tamu berbasis Web diperlukan .

Dalam proses pengisian dan pengolahan data untuk mendapatkan informasi tamu atau pengunjung, perusahaan membuat buku kedatangan tamu diisi oleh tamu itu sendiri dan form bertemu dengan PIC. Pertama-tama tamu datang dan mengisi buku kedatangan tamu tersebut dan memberikan identitas, setelah itu tamu di berikan form bertemu dengan PIC yang nantinya diisi lagi oleh tamu setelah melakukan pertemuan dengan PIC. Selanjutnya seluruh data tamu yang datang pada hari itu akan di kumpulkan dan di input ulang kedalam Microsoft Excel dan dibuat laporan untuk diberikan kepada pimpinan Real Astate Team.

Berdasarkan observasi yang peneliti lakukan, petugas mengalami kesulitan untuk memproses data pengunjung pada PT.Halliburton Indonesia. Sistem yang berjalan sudah menggunakan komputer sebagai sarana dalam pengolahan data, namun dalam mengolah informasi dalam buku tamu masih disimpan secara manual kedalam berkas. Mengenai masalah diatas maka data yang diterima masih mengalami kesalahan, tidak akurat, tidak up to date dan lambat nya dalam membuat dan menyampaikan laporan kepada pimpinan.

Menurut Ladjamudin yang dikutip oleh Suharto \& Ona pada Jurnal INFOKOM Vol.7 No.1 (2019:36), Perancangan yaitu kegiatan yang bertujuan dalam merancang sistem baru yang dapat menyelesaikan masalah yang terjadi yang dapat dengan memilih alternatif sistem yang baik. ${ }^{[1]}$. Menurut Ludwig Von Bartalanfy yang dikutip oleh Alfeno dkk dalam Jurnal SENSI Vol.2 No2 (2016:3), Sistem merupakan seperangkat unsur yang saling terikat dalam suatu antar relasi diantara unsur - unsur tersebut dengan lingkungan. ${ }^{[2]}$. Pendapat Barry E. Cushing yang dikutip oleh Pratita dkk dalam buku Bahan Ajar Sistem Informasi Manajemen (2015:9), Informasi adalah hasil dari pengolahan data yang diorganisasi serta berguna untuk orang yang menerima informasi tersebut. ${ }^{[3]}$. Pendapat Nugroho yang dikutip oleh Sutrisno dkk dalam SENSI Journal Vol.3 No.2 (2017:224), UML (Unified Modeling Language) yaitu perangkat lunak yang berparadigma "berorientasi objek". ${ }^{4]}$

\section{PERMASALAHAN}

Masalah yang ada pada sistem yang berjalan saat ini yaitu :

Untuk pengisian buku tamu masih manual dan tamu yang mengisi sendiri, tamu juga diharuskan mengisi form setelah bertemu dengan PIC dan ditanda tangan oleh PIC. Dan untuk memberikan report atau laporan tamu yang datang setiap bulan petugas harus mencarinya dengan manual dan sangat sulit karna banyaknya buku-buku tamu yang bertumpuk. 


\section{METODE PENELITIAN}

Dalam penelitian ini, digunakan metode penelitian :

\section{Metode Pengumpulan Data}

Pada metode ini data yang digunakan peneliti, yaitu:

\section{Observasi}

Peneliti telah mengamati secara langsung terhadap sistem yang ada saat ini pada PT. Halliburton Indonesia. Dari hasil observasi yang telah dijalankan, peneliti menerima data sebagai sumber informasi sebagai proses analisa dalam merancang sistem yang diperlukan.

2. Wawancara

Dalan metode ini, peneliti melakukan tanya jawab kepada pihak yang berhubungan serta narasumber yang ada pada PT. Halliburton Indonesia secara langsung.

\section{Studi Pustaka}

Pada metode ini, peneliti mengerjakan studi pustaka dengan mengumpulkan, membaca, dan memahami informasi yang terdapat pada berbagai sumber seperti: buku, jurnal, karya tulis, maupun artikel yang bersangkutan dengan masalah yang terjadi.

\section{Metode Analisis}

Metode analisis yang dilakukan oleh peneliti adalah analisis PIECES (Performance, Information, Economic, Control, Efficiency, Service). Sebagai analisis yang digunakan dalam mendapat inti masalah yang lebih spesifik.

\section{Literature Review}

Berikut penelitian yang telah dilakukan dan memiliki hubungan dengan penelitian yang dibahas:

1. Penelitian dalam sebuah jurnal yang dilakukan oleh Syafriyadi (2015) dari Universitas Cokroaminoto Palopo dalam Jurnal Ilmiah d'ComPutarE dengan judul "Perancangan Sistem Informasi Pengolahan Data Administrasi Pada Hotel Rio Rita Palopo". Peneliti mejelaskan masalah yang tedapat pada sistem yang berjalan pada hotel Rio Rita Palopo yaitu pada hotel Rio Rita Palopo mempunyai data-data diantaranya dalah data tamu, data transaksi, data keluar masuk karyawan dan tamu, namun pengolahannya masih menggunakan sistem manual dan memerlukan wktu yang sangat lama dalam proses penyimpanannya, laporan-laporan yang harus menunggu lama masih harus di perbaiki. Dengan adanya permasalahan ini peneliti membuat sistem informasi yang dapat digunakan oleh user untuk memasukan data tamu,data keluar masuk karyawan dan data transaksi setiap tamu, sistem ini di buat agar memudahkan user dalam menyimpan data yang diperlukan pada hotel Rio Rita Palopo. ${ }^{[5]}$

2. Penelitian pada sebuah jurnal yang dilakukan oleh Mulyadi (2019) dari STIKOM Dinamika Bangsa dalam IJCIT (Indonesian Journal on Computer and Information Technology) dengan judul "Aplikasi Buku Tamu Elektronik Pada Perpustakaan STIKOM Dinamika Bangsa", pada penelitian yang dilakukan oleh peneliti menjelaskan bahwa masalah yang terjadi yaitu ketika banyak pengunjung perpustakaan mengalami antrian pengisian buku tamu sehingga banyak yang memilih langusung masuk kedalam tanpa mengisi buku tamu terlebih dahulu, adapun masalah yang terjadi yaitu ketika merekap data pengunjung yang datang user mengalami kesulitan dan memerlukan waktu yang lama. Sehingga dengan adanya sistem ini pengisian tamu pada perpustakaan akan lebih teratur, saat user membutuhkan data tamu yang datang akan lebih cepat dan penyimpanannya lebih aman serta terintegrasi. Pada sistem ini bahasa yang digunakan ialah bahasa pemrograman PHP dan database MySQL. ${ }^{[6]}$

3. Penelitian yang dilakukan oleh Siska Makmur (2018) yang berjudul "Perancangan Sistem Informasi Buku Tamu Dan Kehadiran Pegawai Di PT Bio Farma (Persero)". Penelitian ini bertujuan untuk mempermudah user untuk pengecekan tamu yang 
berkunjung dan keluar masuk karyawan pada PT Bio Farma (persero),mengetahui masalah tersebut user cukup kesulitan dalam membuat laporan tamu yang berkunjung dan laporan keluar masuknya karyawan pada PT Bio Farma (persero). Berdasarkan masalah diatas peneliti mengusulkan pembuatan sistem tersebut dengan cara pengoprasian yang cukup mudah dan dapat menyimpan data - data atau laporan di tempat yang aman sehingga data data yang ada tidak mudah hilang dan juga penyimpanan data lebih terintegrasi. ${ }^{[7]}$

4. Penelitian dalam sebuah jurnal yang dilakukan oleh Syafriyadi (2015) dari Universitas Cokroaminoto Palopo dalam Jurnal Ilmiah d'ComPutarE dengan judul "Perancangan Sistem Informasi Pengolahan Data Administrasi Pada Hotel Rio Rita Palopo". Peneliti mejelaskan permasalahan yang ada pada sistem yang berjalan pada hotel Rio Rita Palopo yaitu pada hotel Rio Rita Palopo mempunyai data-data diantaranya dalah data tamu, data transaksi, data keluar masuk karyawan dan tamu, namun pengolahannya masih menggunakan sistem manual dan memerlukan wktu yang sangat lama dalam proses penyimpanannya, laporan-laporan yang harus menunggu lama masih harus di perbaiki. Dengan adanya permasalahan ini peneliti membuat sistem informasi yang dapat digunakan oleh user untuk memasukan data tamu,data keluar masuk karyawan dan data transaksi setiap tamu, sistem ini di buata agar memudahkan user untuk menyimpan data - data yang dibutuhkan pada hotel Rio Rita Palopo. Sistem ini dibuat menggunakan Visual Basic 6.0. ${ }^{[8]}$

5. Penelitian yang dilakukan oleh Robby Alamsyah (2010) yang berjudul "Perancangan Sistem Aplikasi Buku Tamu Internet Public Umum menggunakan Visual Basic Pada Dinas Komunikasi dan Informatika Kota Bandung". Dalam penelitian ini, penulis menjelaskan bahwa sistem yang berjalan dalam pengelolaan data tamu yang menggunakan internet public umum masih manual. Oleh, karena itu penulis membuat rancangan sistem usulan pengelolaan data tamu berbasis web yang berguna untuk mengontrol pemakaian internet public umum oleh tamu sekaligus membuat laporan kujungan tamu yang efektif. Dalam perancangan sistem aplikasi buku tamu ini, penulis menggunakan software visual basic dan database menggunakan Ms. Access. ${ }^{[9]}$

\section{HASIL DAN PEMBAHASAN}

Pada penelitian ini, akan dibahas perihal pembuatan sistem informasi e-guest book pada PT Halliburton Indonesia. Pada penelitian ini, penulis mengusulkan sistem usulan yang dapat mengolah informasi data tamu. Untuk melakukan penelitian pada masalah yang terjadi, serta tidak keluar dari pokok pembahasan, penulis fokus pada bagaimana mengolah data tamu mulai dari tamu datang hingga tamu selesai dengan urusan nya pada PT Halliburton Indonesia.

\section{Analisis PIECES}

1. Kinerja Sistem (Performance)

Sistem yang berjalan pada saat ini masih menggunakan sistem manual, yaitu dengan tamu mengisi buku tamu secara manual,dan setelah itu petugas mengetik ulang data tamu perhari kedalam excel.dikarenakan tamu yang mengisi buku tersebut petugas kesulitan saat menginput kembali kedalam excel karena tulisan yang berbeda, waktu yang diperlukan cukup lama dan tidak efisien karena menjadi pekerjaan yang berulang.

\section{Informasi (Information)}

Akurat - petugas sering mengalami kesulitan saat menginput data kembali kedalam excel karena tulisan tamu yang sulit di baca.contohnya seperti nama tamu dan berasal dari instansi mana. Tepat waktu- laporan data tamu yang di input kedalam excel membutuhkan waktu yang cukup lama, dan terkadang tidak akurat.

3. Ekonomi (Economy) 
Biaya - biaya pada sistem yang berjalan pada saat ini untuk jangka panjang akan membutuhkan biaya yang banyak untuk membeli buku dan alat tulis.

4. Keamanan (Control)

Keamanan dan control- pada sistem yang berjalan petugas yang menerima tamu tidak ditentukan, terdapat resiko human error pada saat proses penginputan kedalam excel.

5. Efesiensi (Efeciency)

Banyaknya waktu yang terbuang dalam pendataan disebabkan masih menggunakan buku dan menginputkan kembali kedalam excel sehingga menjadi tidak efektif

6. Layanan(Service)

Pada sistem yang berjalan terjadi keterlambatan pencatatan dan pencarian data tamu masih mengguanakan cara manual, dengan data yang menumpuk sehingga memerlukan cukup banyak waktu untuk mendapatkannya.

Use Case Diagram yang menggambarkan secara umum Sistem informasi e-guest book yang berjalan saat ini menggambarkan alur sistem dengan use case dan aktor yang terlibat. Berdasarkan diagram, terdapat 3 aktor yang dapat melakukan kegiatan didalam sistem, yaitu tamu, security dan PIC. Juga terdapat 11 (sebelah) Use Case yang dapat dilakukan oleh aktor tersebut.

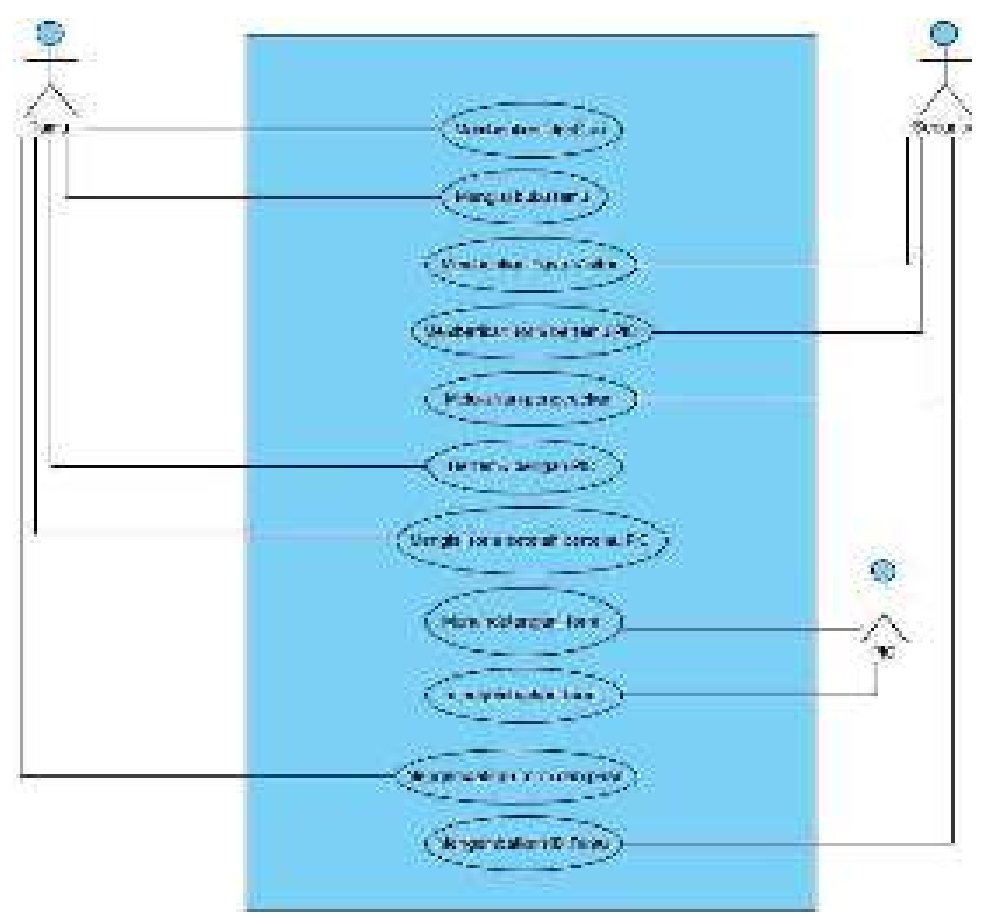

Gambar 1. Use Case Sistem Informasi e-guest book

\section{RANCANGAN SISTEM}

Dalam menangani permasalahan yang terjadi, diperlukan rancangan Sistem Informasi untuk $e$ guest book berbasis web. Sehingga, informasi mengenai data tamu menjadi lebih akurat. Datadata tamu dapat langsung diinput pada sistem sehingga lebih efektif dan efisien. Pada sistem ini, security dapat mengelola data tamu dengan mudah.

\section{Use Case Diagram}


ISSN : $2356-5195$

Online ISSN: 2654 - 8704

Berikut ialah Use Case Diagram Rancangan Sistem Informasi e-guest book Berbasis Web yang menjabarkan alur sistem menggunakan use case dan aktor-aktor yang terlibat :

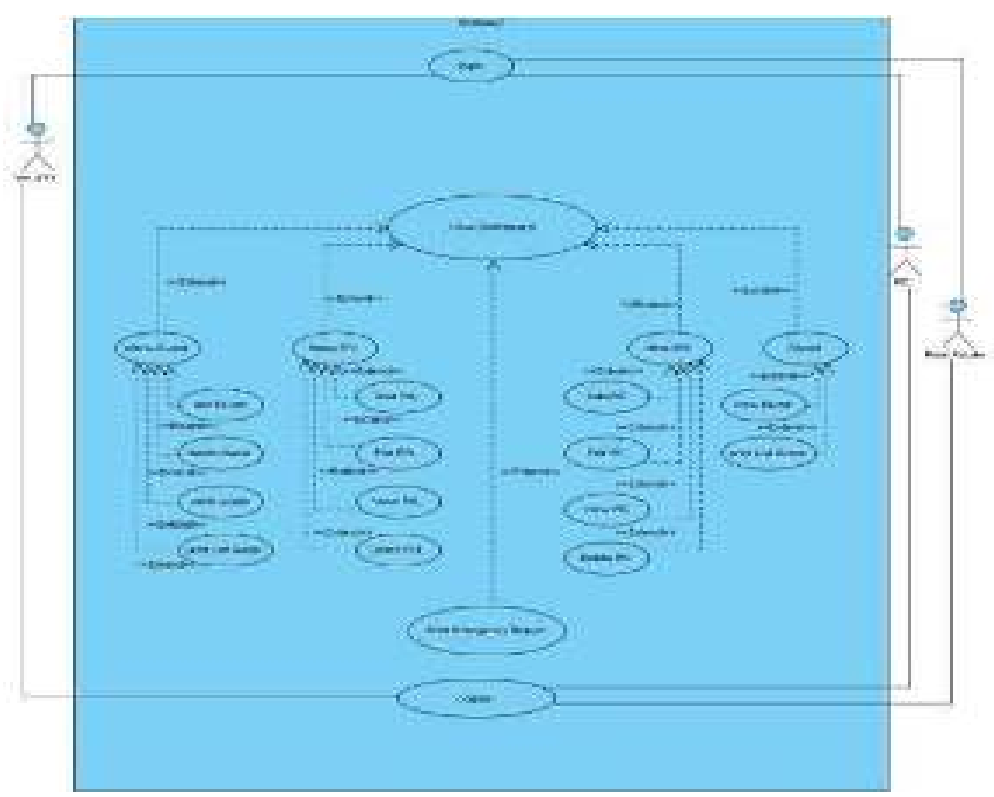

Gambar 2. Use Case rancangan Sistem Informasi e-guest book

Pada diagram di atas, terdapat 1(satu) sistem yang mencakup seluruh kegiatan, 3 (tiga) actor yang melakukan kegiatan yaitu admin dan 22 usecase yang akan dilakukan oleh aktor tersebut.

\section{Class Diagram}

Class diagram (diagram kelas) yang membantu dalam visualisasi kelas pada suatu sistem. Berikut class diagram Sistem Informasi E-guest book berbasis web:

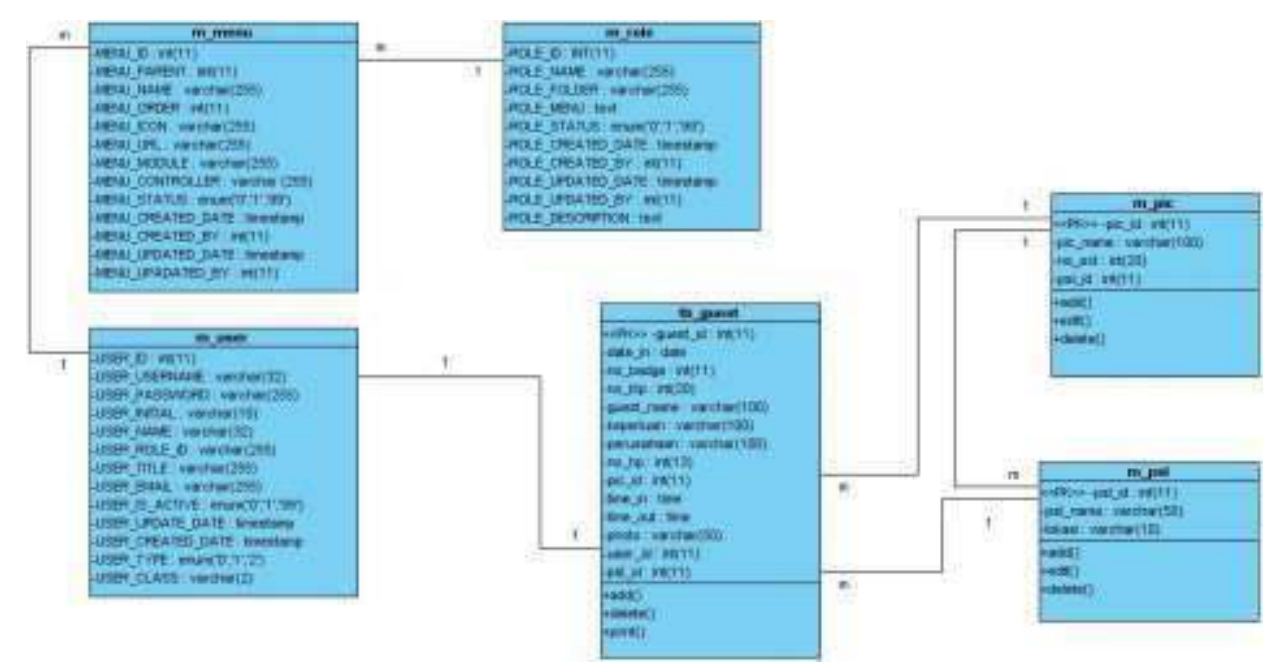

Gambar 3. Class Diagram rancangan Sistem Informasi E-guest book

Diagram kelas Rancangan Sistem Informasi E-guest book yang menjelaskan rancangan basis data yang akan diperlukan pada sistem. 
ISSN : $2356-5195$

Online ISSN: 2654 - 8704

\section{Tampilan Rancangan Sistem}

Berikut ini tampilan rancangan e-guest book berbasis web:

1. Tampilan Halaman Login

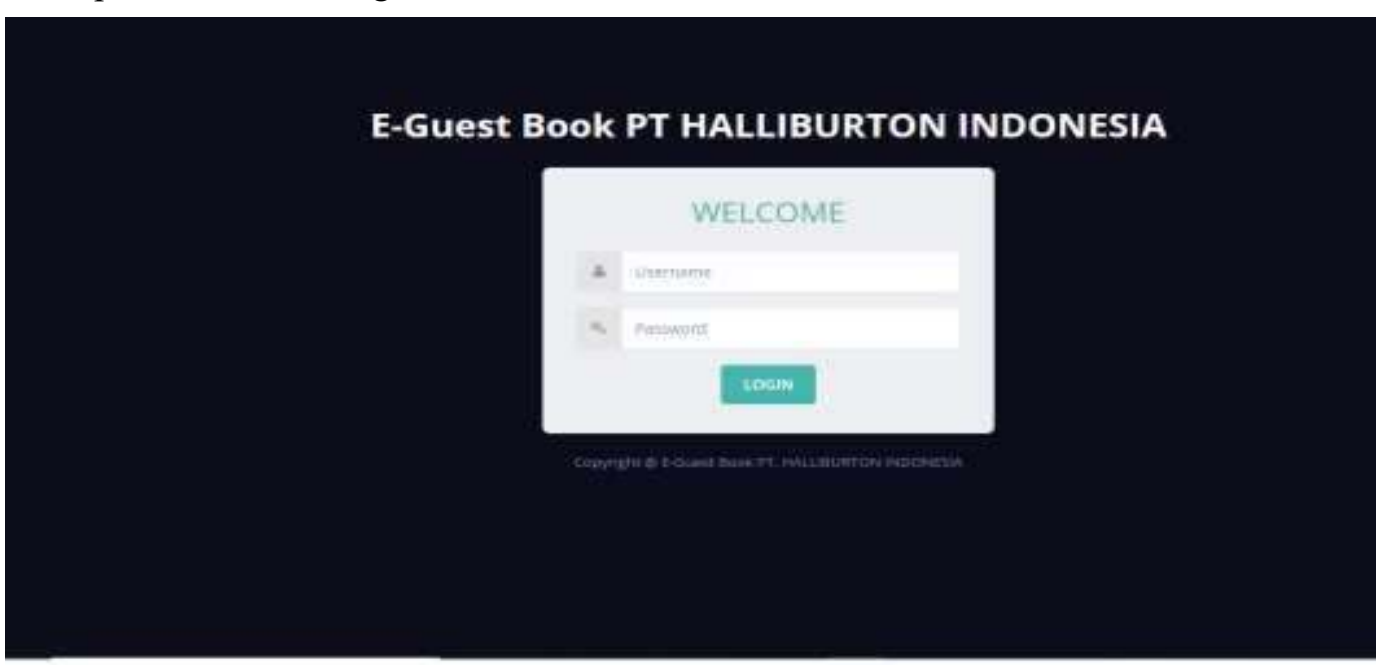

Gambar 4. Tampilan login

Tampilan diatas merupakan tampilan awal sebelum masuk kehalaman sistem, setiap user harus melakukan login dengan memasukan username dan password yang benar agar dapat masuk kedalam sistem.

2. Tampilan Dashboard

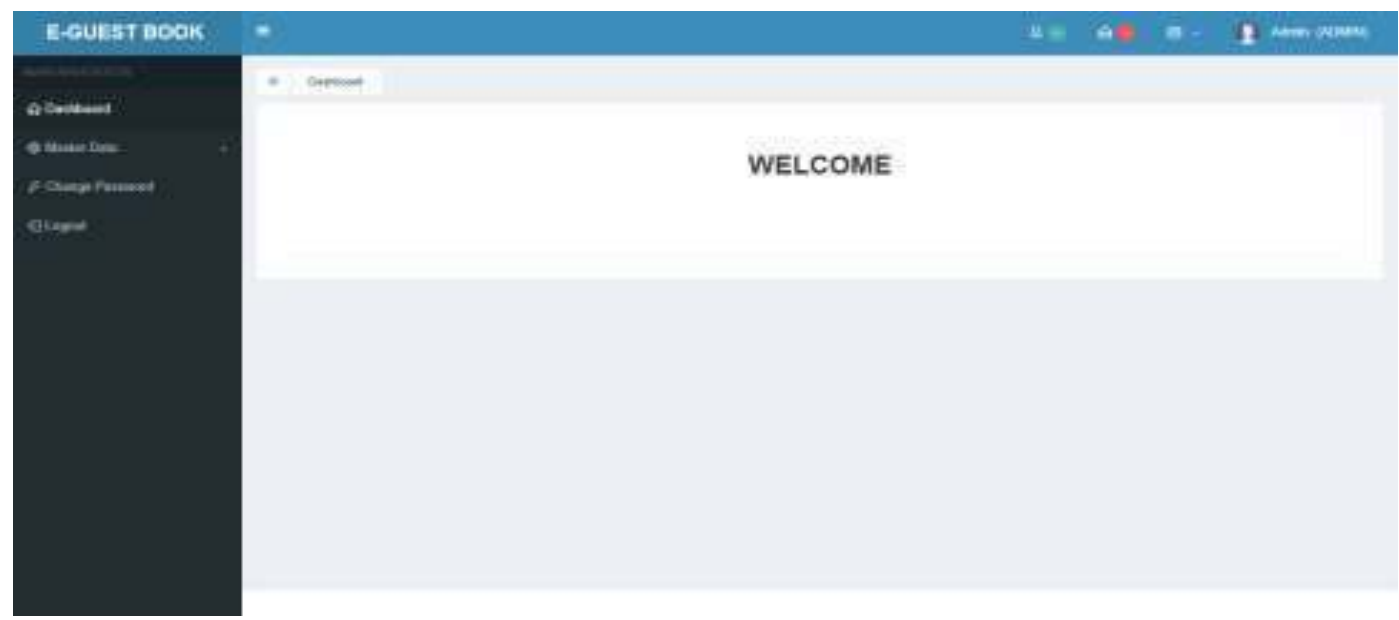

Gambar 5. Tampilan dashboard

Tampilan diatas adalah tampilan dari halaman Dashboard.

3. Tampilan Form Guest

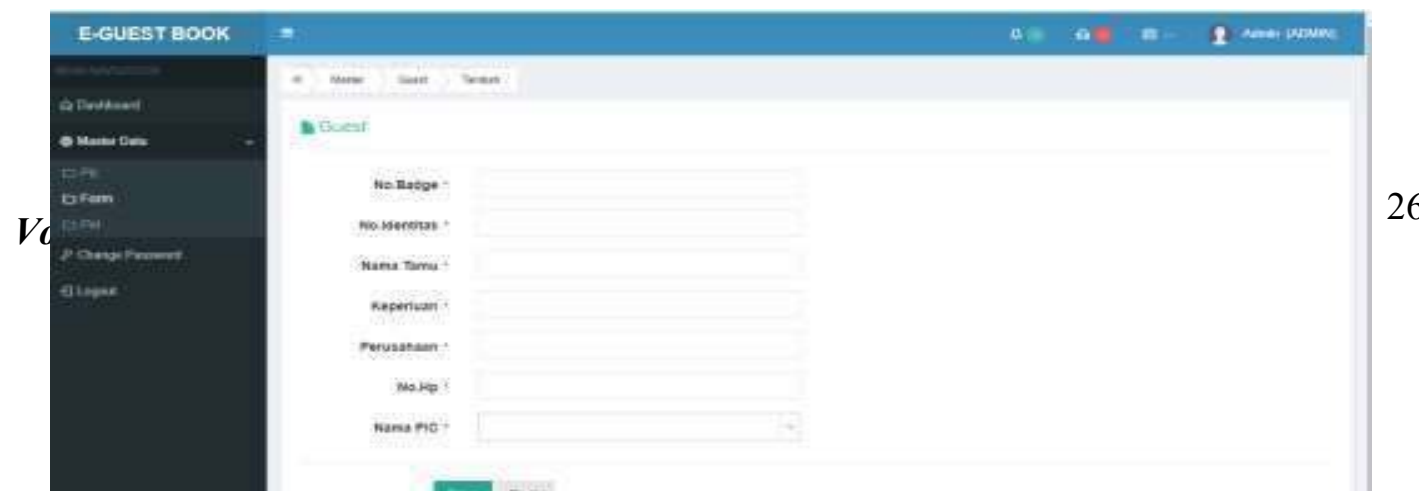




\section{Gambar 6. Tampilan form guest}

Tampilan diatas adalah tampilan dari halaman Form Guest yang akan diisi oleh Security pada saat pengunjung datang. Form Guest berisi No. Badge, No. Identitas , Nama Tamu, Keperluan, Perusahaan, No. Hp, Dan Nama PIC.

4. Tampilan Table Guest

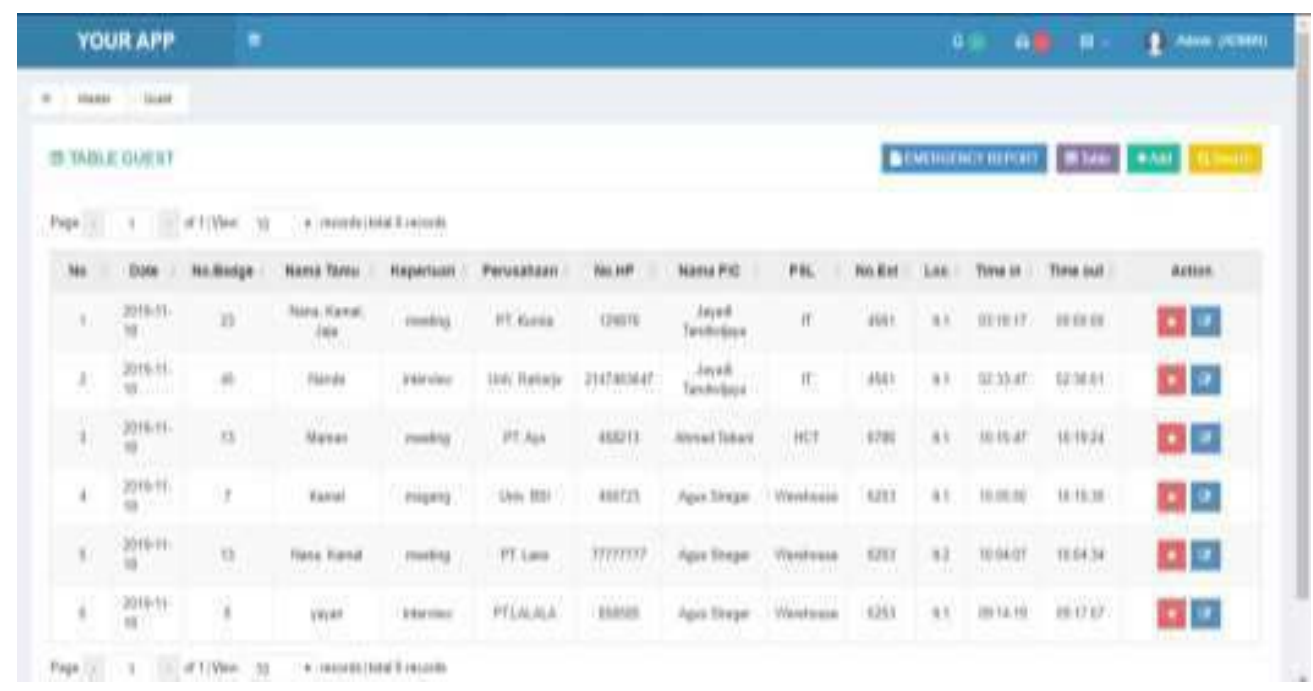

Gambar 7. Tampilan table guest

Tampilan diatas merupakan tampilan Table Pengunjung atau Guest, yang berisi data - data pengunjung yang ingin bertemu dengan PIC pada PT Halliburton Indonesia.

5. Tampilan Form PIC

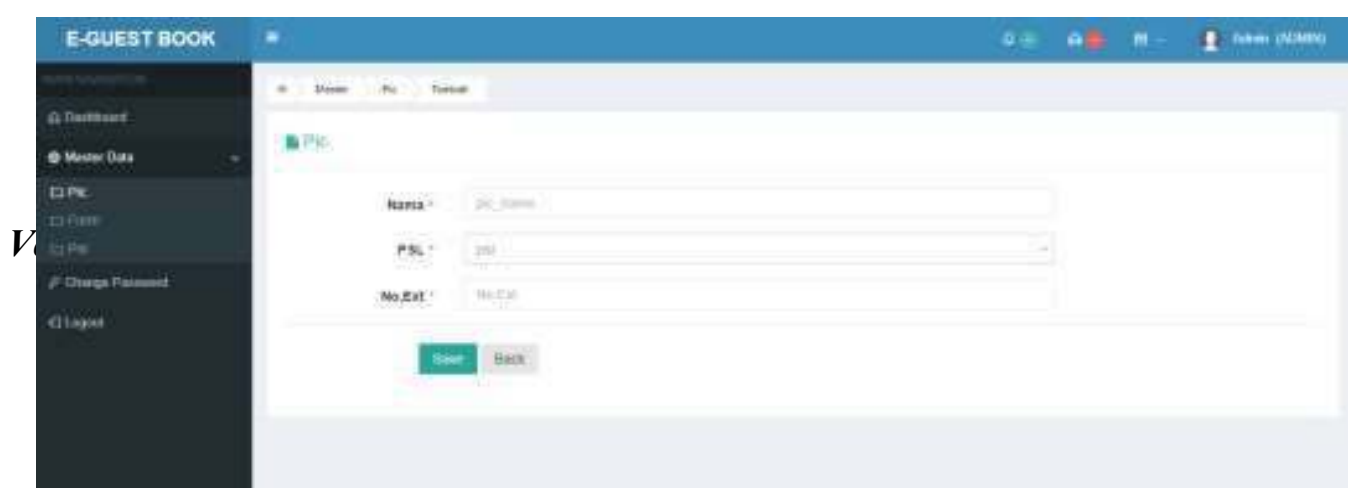


Gambar 8. Tampilan form PIC

Tampilan diatas adalah tampilan dari halaman Form PIC yang akan diisi oleh Real Astate, di form PIC tersebut berisi Nama PIC, PSL, dan No. Ext.

6. Tampilan Table PIC

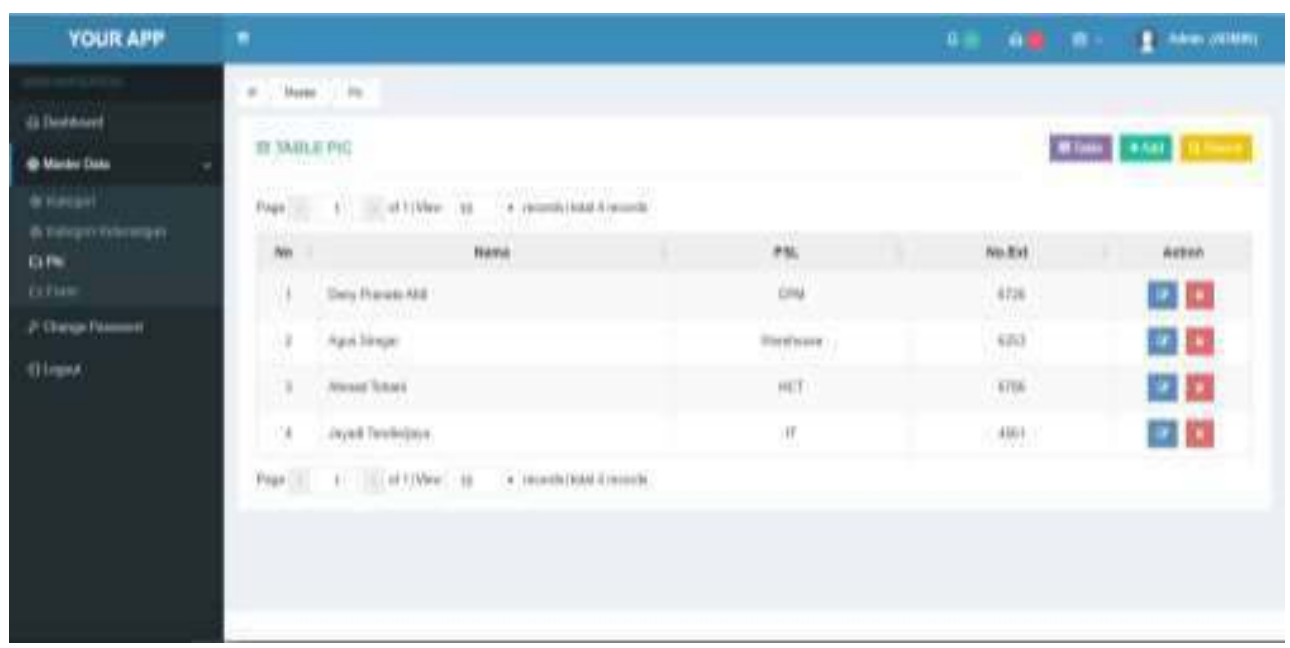

Gambar 9. Tampilan table PIC

Tampilan diatas adalah tampilan dari Table PIC. setelah mengisi form PIC, data - data PIC yang dimasukan akan masuk kedalam halaman table seperti ini.

7. Tampilan Form PSL

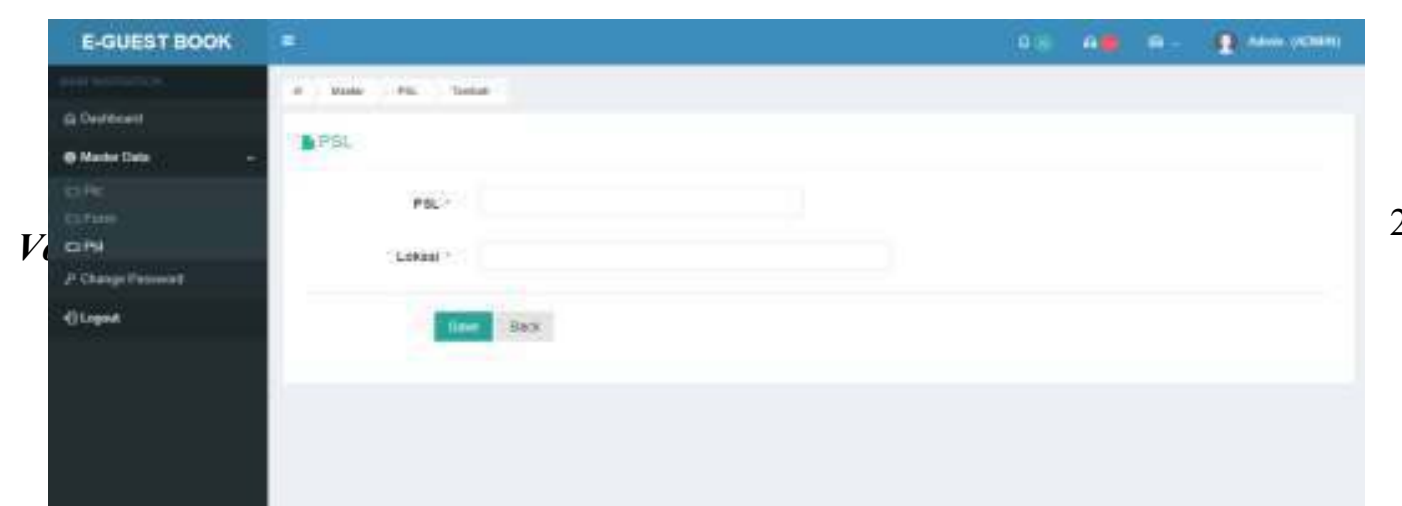


Gambar 10. Tampilan form PSL

Tampilan diatas adalah tampilan dari halaman Form PSL yang akan diisi oleh Real Astate, di form PSL tersebut berisi Nama PSL, dan lokasi PSL tersebut.

8. Tampilan Table PSL

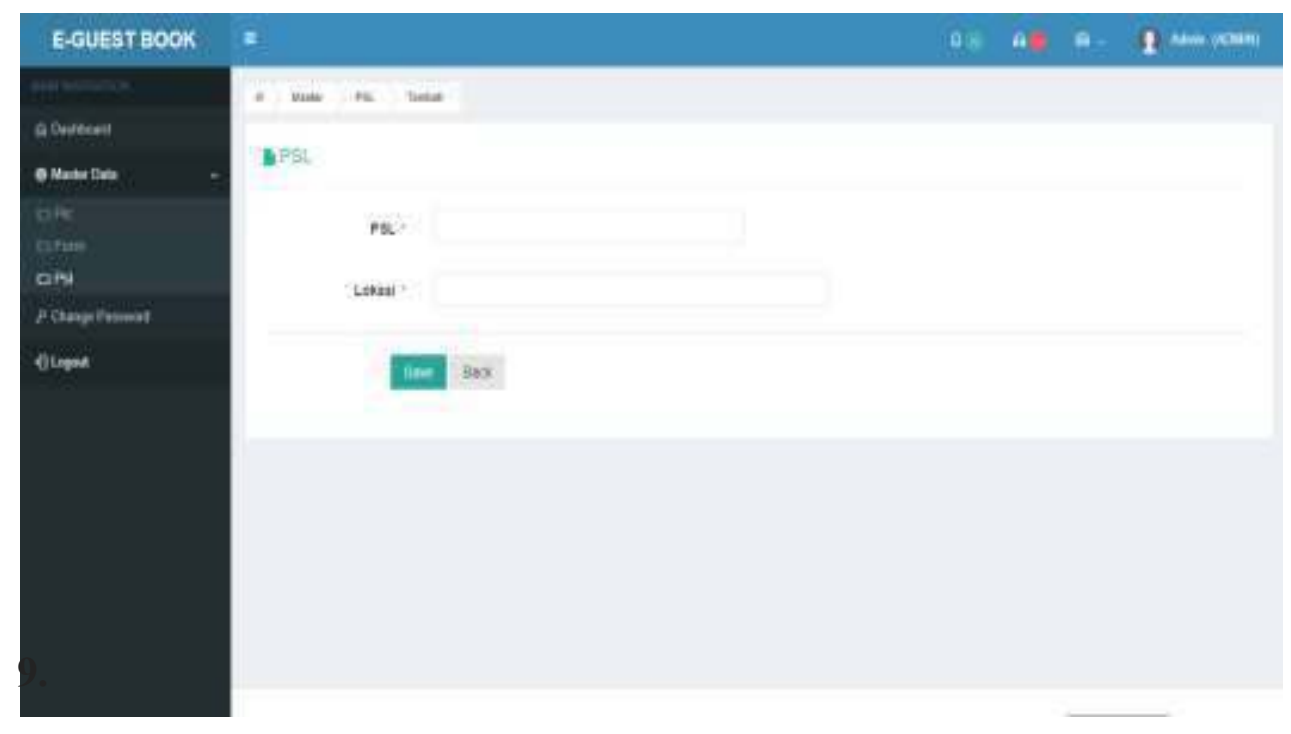

Gambar 11. Tampilan table PSL

Tampilan diatas adalah tampilan dari Table PSL. setelah mengisi form PSL, data - data PSL yang dimasukan akan masuk kedalam halaman table seperti ini.

\section{KESIMPULAN}

Sistem informasi e-guest book pada PT Halliburton Indonesia memiliki manfaat untuk dapat membantu proses pengolahan data tamu, data tamu yang datang menjadi lebih efektif dan akurat. Dengan sistem ini, dapat mempermudah perusahaan dalam mengolah informasi mengenai data tamu. Untuk mendapatkan sistem yang dapat menyimpan data tamu dengan rapih, mengurangi resiko kehilangan data - data tamu, dan mempercepat petugas dalam pembuatan laporan mengenai data tamu. 


\section{SARAN}

Pada sistem yang saat ini pengoperasiannya masih menggunakan Buku Tulis Tamu yang lebih baik diubah menjadi sistem yang terkomputerisasi sehingga dapat melakukan proses pengolahan data secara tepat dan cepat. Perlu adanya backup data setiap perminggu atau perbulan agar tidak terjadi hal yang tidak diinginkan dalam penyimpanan data. Dan diperlukan sosialisasi dan training untuk menerapkan sistem yang baru, agar dapat memaksimalnya kinerja petugas terkait.

\section{DAFTAR PUSTAKA}

[1] Pamungkas, Canggih Ajika dan Sudarmaji. 2015. Rancang Bangun E-Learning Center Berbasis Web Untuk Meningkatkan Kualitas Dan Kuantitas Media Pembelajaran Yang Efektif. Jurnal INFORMA Politeknik Indonusa Surakarta. 1(2). ISSN : 2442-7942.

[2] Alfeno, S., Sudarto, F., \& Maulana, I. (2016). Penerapan Analytical Hierarchy Process ( Ahp) Sebagai Model Penunjang Keputusan Penerimaan Mahasiswa Program Studi Ground Handling Airlines Pada Universitas Muhammadiyah Tangerang. SENSI Journal, 2(2), 139153.

[3] Pratita, D. (2015). Bahan Ajar Sistem Informasi Manajemen. Yogyakarta: Deepublish.

[4] Sutrisno, S., Kristiadi, D. P., \& Supriyanti, D. (2017). Aplikasi Sistem Pakar Untuk Mendiagnosa Gangguan Jaringan Lan Berbasis Android Di Sekolah Kemurnian Jakarta. SENSI Journal, 3(2), 221-239.

[5] Syafriadi, S. (2015). Perancangan Sistem Informasi Pengolahan Data Administrasi pada Hotel Rio Rita Palopo. d'ComPutarE: Jurnal Ilmiah Information Technology, 4(1), 1-7.

[6] Mulyadi, M. (2019). Aplikasi Buku Tamu Elektronik Pada Perpustakaan STIKOM Dinamika Bangsa. IJCIT (Indonesian Journal on Computer and Information Technology), 4(1).

[7] Solihin, C. (2018). Perancangan sistem informasi buku tamu dan kehadiran pegawai di PT. Bio Farma (persero): laporan kerja praktek.

[8] Syafriadi, S. (2015). Perancangan Sistem Informasi Pengolahan Data Administrasi pada Hotel Rio Rita Palopo. d'ComPutarE: Jurnal Ilmiah Information Technology, 4(1), 1-7.

[9] Riswandi, R. (2010). Perancangan Sistem Aplikasi Buku Tamu Internet Public Umum Menggunakan Visual Basic.

[10] Puspita Dewi, N. (2013). Perancangan Sistem Informasi Pengelolaan Data Tamu Dan Pengunjung Di Museum Geologi (Doctoral dissertation, Universitas Komputer Indonesia). 